\title{
Abordagem do manejo de Resíduos na Construção Civil, à luz da legislação
}

\author{
Approach to Waste management in Construction, in light ofthe legislation
}

Maria Paula Viana Baptista $^{\dagger *}$, Cleber José Fermiano Paschoal ${ }^{\dagger}$

Como citar esse artigo. Baptista, MPV; Paschoal, CJF. Abordagem do manejo de Resíduos na Construção Civil, à luz da legislação. Revista Teccen. 2019 Jan/Jun; 12 (1): 08-22.

\begin{abstract}
Resumo
Com a degradação cada vez maior do meio ambiente, há a necessidade de cuidados com os resíduos gerados e o estudo das legislações e normas vigentes. As leis e normas referentes a este tema, abrange um grande leque de parâmetros e diretrizes a serem seguidos, fazendo com que o responsável pela obra não só cumpra as obrigações, como aumente a produtividade do serviço, diminuem desperdícios e evite problemas futuros com a justiça. Fazendo com que, custos desnecessários sejam conjurados e evite penalizações, tais como, multas, restrições de serviço, embargo e demolição da obra. Tendo em vista que a Construção Civil é um dos setores que mais geram resíduos no país, é indispensável o estudo dessas variáveis relacionadas, gestão e penalidades vigentes. Com o objetivo de trazer uma abordagem clara à luz da legislação,sendo que não se trata de uma disciplina técnica dos cursos afins, para que o profissional possa realizar uma reflexão sobre a importância dos assuntos tratados.

Palavras-Chave: Meio ambiente, Resíduos da Construção Civil, Penalidades, Gestão.
\end{abstract}

\section{Introdução}

\section{Processo condutivo de construção}

O crescimento da sociedade vem se ampliando cada vez mais e com isso a indispensabilidade de novas moradias, novos prédios, reformas, obras em gerais, dessa maneira a necessidade do uso contínuo da construção civil. Este setor é de grande importância para a economia brasileira, gerando um crescimento social e econômico. Porém, também se gera um crescimento negativo referente aos impactos ambientais (Pinto, 2005 apud Karpinski et al., 2009).

Além do impacto gerado pelo grande consumo desses materiais, que são retirados da natureza a sua matéria-prima, possui outro agravante, que são os resíduos gerados no processo de construção, pois, mais da metade dos resíduos do país são decorrentes desse setor.

\section{Resíduos Sólidos no Brasil}

A Lei Federal n¹2.305/2010, conceitua resíduos sólidos como:

"material, substância, objeto ou bem descartado resultante
de atividades humanas em sociedade, a cuja destinação
final se procede, se propõe proceder ou se está obrigado
a proceder, nos estados sólido ou semissólido, bem
como gases contidos em recipientes e líquidos cujas
particularidades tornem inviável o seu lançamento na rede

Afiliação dos autores: † Discente do Curso de Graduação de Engenharia Civil na Universidade de Vassouras, Vassouras/RJ, Brasil.

* Docente da Universidade de Vassouras, Vassouras/RJ, Brasil.

* Email para correspondência: mpvbaptista@gmail.com 
pública de esgotos ou em corpos d'água, ou exijam para isso soluções técnica ou economicamente inviáveis em face da melhor tecnologia disponível (PNRS, 2010, p.1).”

Esses resíduos podem ser classificados conforme o seu risco e origem:

Origens: domiciliar, hospitalar, transportadoras ou mineradoras, limpeza urbana, resíduo de indústrias, construção, saneamento etc.

Riscos: Não perigosos e perigosos.

Segundo Abrelpe (2017), os resíduos sólidos gerados no Brasil anualmente chegam a 78,4 milhões de toneladas, sendo que a coleta abrange somente $91,4 \%$ desses rejeitos. Com isso, pode-se observar que certa de $6,9 \%$ não são destinados adequadamente para os seus fins. Sendo o Sudeste estado com maior índice de geração desses resíduos com 52,9\%, como podemos ver na tabela e imagem abaixo.

\section{Resíduos da Construção Civil e Demolições}

As regulamentações de gerenciamento de Resíduos Sólidos do Estado de Nova York, 6NYCRR, part. 360 (BIOCYCLE,1990) apud Zordan (1997), define RCD (Resíduos da Construção Civil e Demolição), como:

\footnotetext{
"Resíduos de construção e demolição são resíduos sólidos não contaminados, provenientes da construção, reforma, reparos e demolição de estruturas e estradas, e resíduos sólidos não contaminados de vegetação, resultantes da limpeza e escavação de solos. Como resíduos, incluem-se, mas não limitam-se, blocos, concreto e outros materiais de alvenaria, solo, rocha, madeira, forros, argamassa, gesso, encanamentos, telhas, pavimento asfáltico, vidros, plásticos que não camuflem outros resíduos, fiação elétrica e equipamentos que não contenham líquidos perigosos e metais que estiverem num dos itens acima".
}

Apesar de o setor da Construção Civil ter decaído nos últimos anos devido à economia, esse ramo tem um

Tabela 1. Quantidade de Resíduos Sólidos Urbanos -RSU/dia Coletados por Regiões e Brasil

\begin{tabular}{lcc}
\hline Regiões & $\mathbf{2 0 1 6}$ & $\mathbf{2 0 1 7}$ \\
\hline Norte & 12500 & 12705 \\
Nordeste & 43555 & 43871 \\
Centro-Oeste & 14175 & 14406 \\
Sudeste & 102620 & 103741 \\
Sul & 20987 & 21327 \\
Brasil & 193637 & 196050 \\
\hline
\end{tabular}

vasto mercado dentro do país. Com isso, há necessidade constante de construções de novas moradias, prédios e demolições. Acarretando com isso, um grande volume de insumos gerados, sendo responsável por cerca de 41 a 70\% dos despojos sólidos produzidos em todo o país Pinto e Gonzáles (2005). Podendo variar, as categorias de substrato e a sua porcentagem conforme com o material:

\section{Perdas do processo construtivo}

Como se pode se observar no gráfico acima, a uma ramificação sobre a capacidade dos despojos gerados nas obras, $59 \%$ são das reformas, $21 \%$ de novos prédios e $20 \%$ nas novas moradias residências, segundo IEMA do Espírito Santo. Sendo assim, é necessário traçar quais etapas são provenientes essas perdas:

\section{Superprodução}

A perda relacionada a superprodução está conectada a fabricação excessiva ou processo de matérias que possui validade para o seu uso. Podendo também ter perdas em matéria-prima, tempo e serviço com preparo de matérias antes do seu prazo de uso. Exemplo que se pode dar a essa perda seria a elaboração de concreto a mais do que o necessário. 


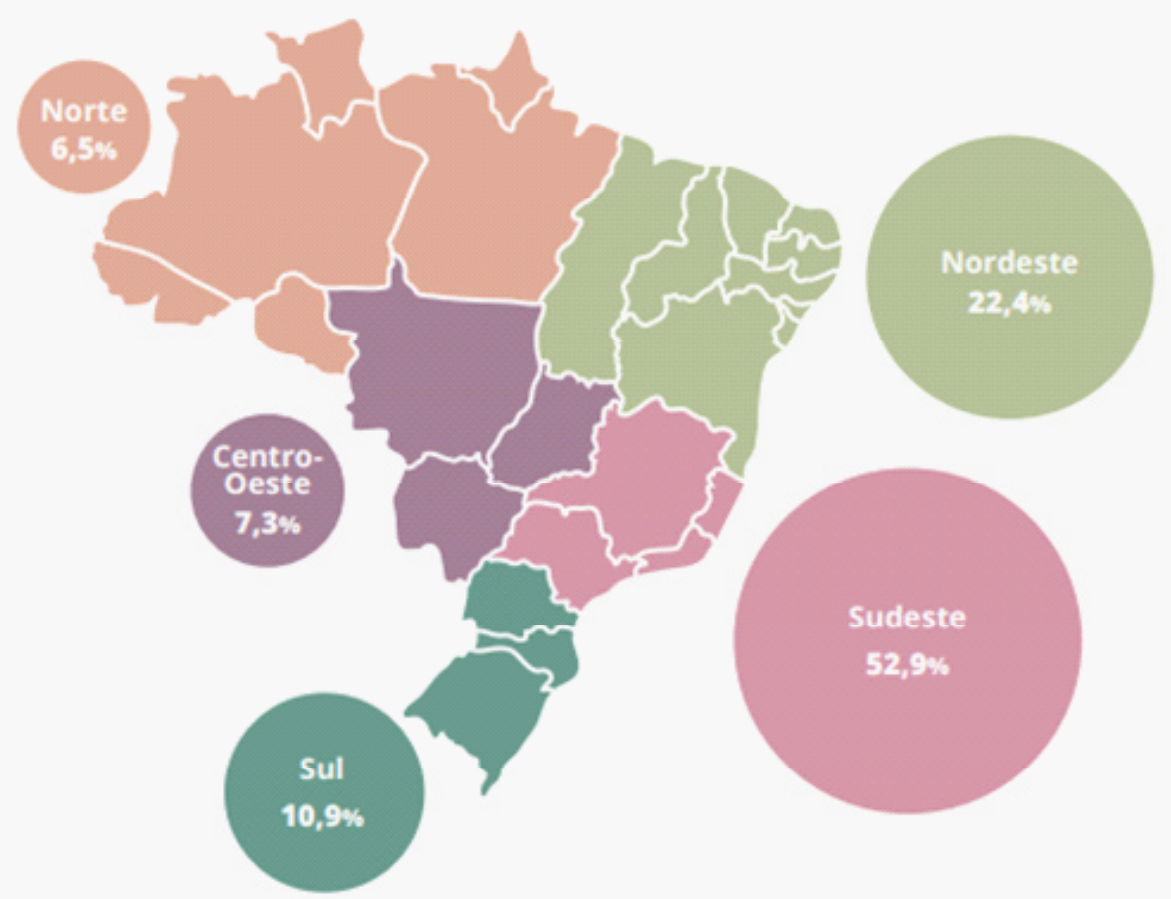

Figura 1. Participação das Regiões do País no Total de Resíduos Sólidos Urbanos (RSU) Coletados. Fonte: Abrelpe (2017).

Gráfico 1. Somatório dos tipos de Resíduos da Construção (RSU) no Brasil.

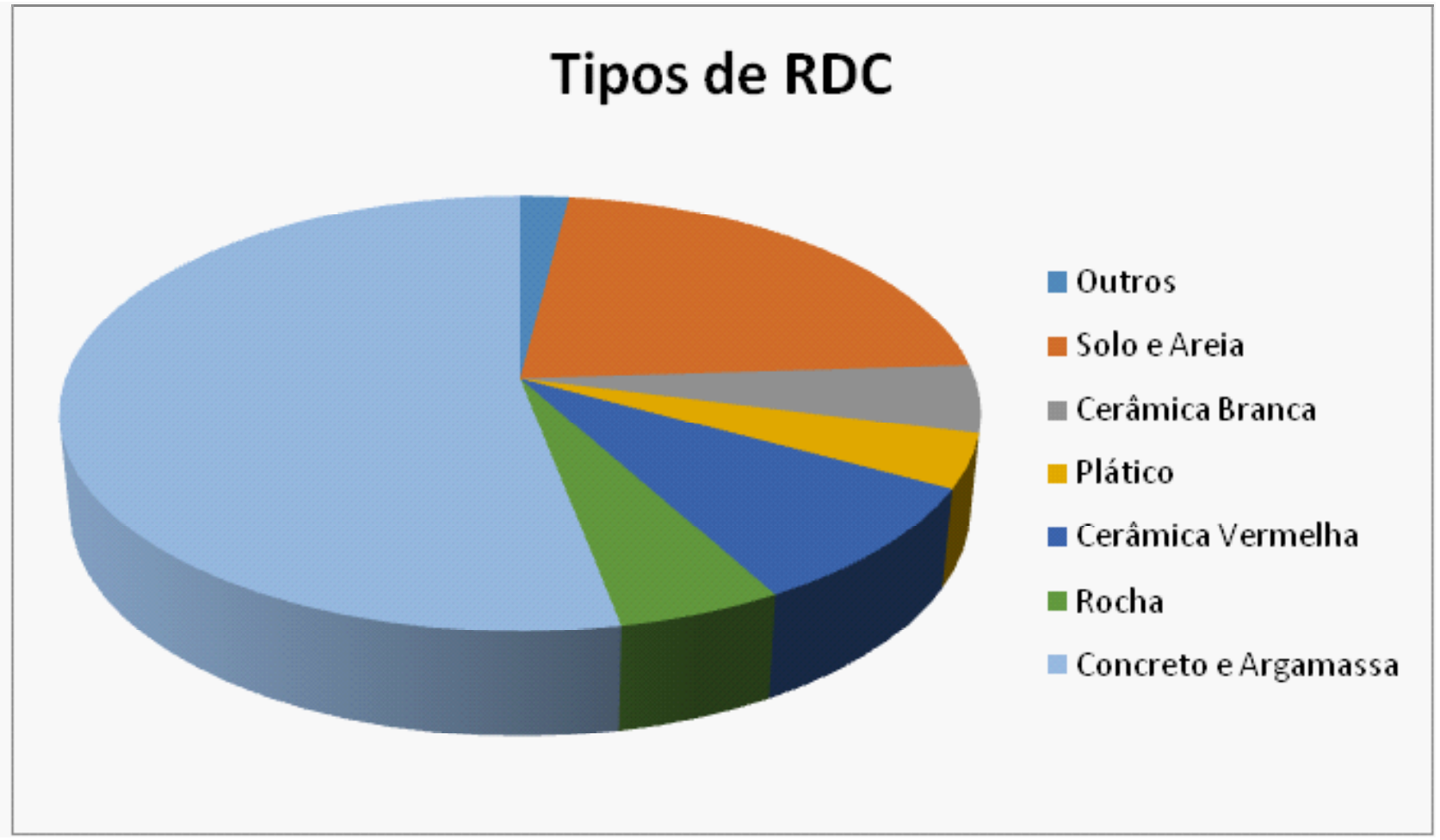

Fonte: (Silva, 2001). 
Gráfico 2. Composição dos Resíduos Sólidos Urbanos.

\section{Tipo de Construção}

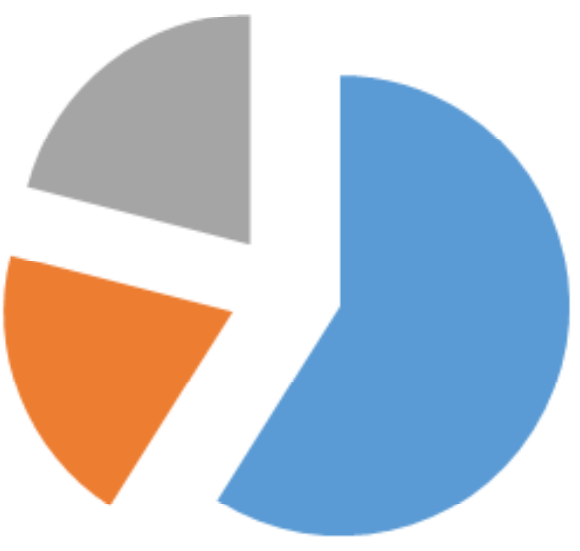

Reformas (59\%)

Residência Nova (20\%)

Orédios Novos (21\%)

Fluxograma 1. Relação de Perdas do Processo Construtivo da Construção Civil.

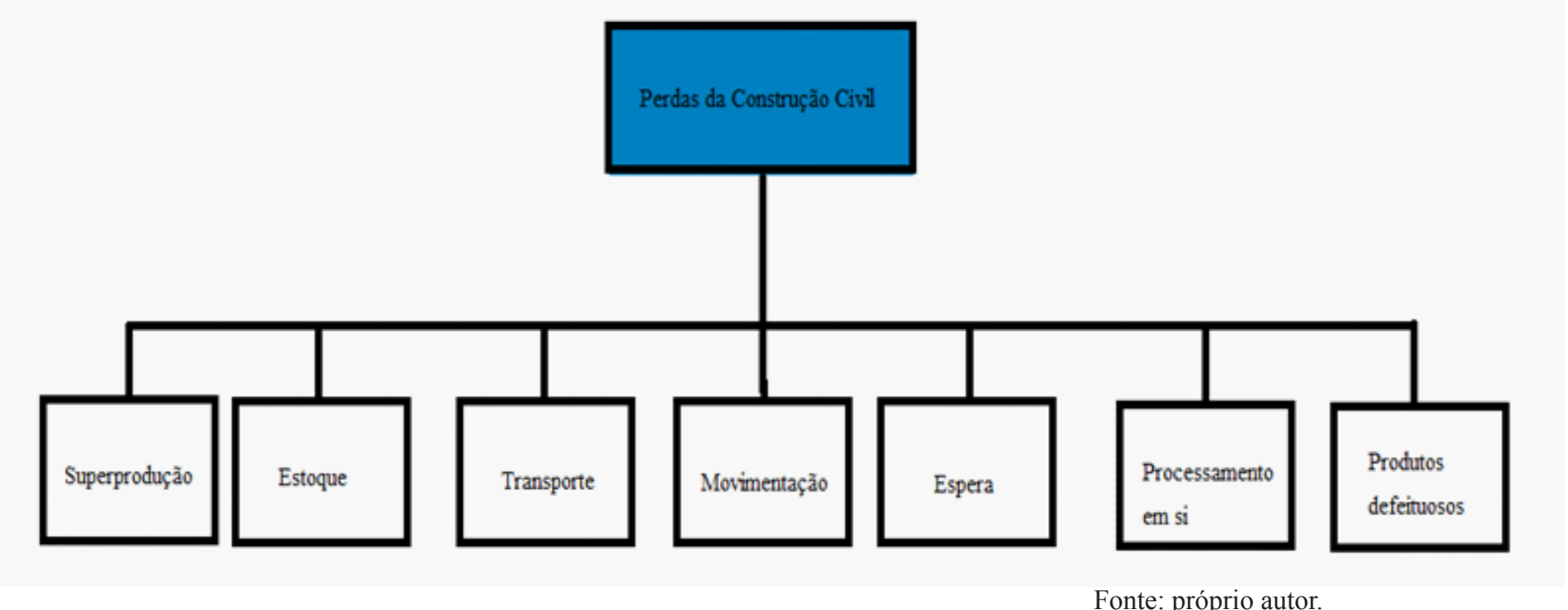

Fonte: próprio autor.

\section{Estoque}

Os resíduos gerados no estoque são diretamente relacionados com a gestão desse local. Pois, um estoque com alto teor de material ou má administração, podem acarretar perdas diretas e indiretas. Sejam elas por produtos fora da validade, inacabados, que não são armazenados adequadamente, roubos, ou até desuso de equipamentos.

\section{Transporte}

Esse dano esta, relacionado ao manuseio do material, podendo ocorrer por erro ou um simples acidente. Como quedas de tijolos, rasgo de sacos de areia/cimento.

\section{Movimentação}

A movimentação está diretamente relacionada, aos funcionários da obra, a esforços repetitivos desnecessários como percorrer um certo perímetro para pegar materiais/ferramentas, fazendo com que haja uma perca na produtividade do serviço.

Segundo Costa \& Formoso (1999), essas perdas 
estão relacionadas a:

a. Mal layout;

b. Falta de organização;

c. Método de trabalho não traçado;

d. Escassez de maquinário necessário para realizar as atividades da obra;

e. Insatisfação do colaborador pelas instalações associadas as suas necessidades (refeitório, banheiro etc.).

\section{Espera}

Como o próprio nome diz, esta perda está relacionada à espera de trabalho, maquinário ou material para término, ou continuidade de determinado processo construtivo. Como um concreto que está sendo preparado na betoneira e o funcionário responsável por esse processo, não conferiu a matéria-prima e não tinha agregado suficiente.

\section{Produtos defeituosos}

Ocorre quando se é construído algo fora do padrão estabelecido no projeto. Podendo ser causado por:

a. Falta de inspeção ou inadequada;

b. Materiais defeituosos;

c. Materiais qual qualidade inferior do que especificado; d. Ausência de capacitação aos colaboradores.

Além dos resíduos gerados por esses produtos incorretos, há uma perda na produtividade e no desempenho, em geral.

\section{Processamento}

Para Meira et al. (1998), esses donos:

\begin{abstract}
"Originam-se na natureza das atividades do processo ou na execução inadequada dos mesmos, decorrentes da falta de procedimentos padronizados e ineficiências nos métodos de trabalho, da falta de treinamento dos operários ou deficiências no detalhamento e construção dos projetos".
\end{abstract}

Provenientes de atividades ou processos desnecessários ou necessários, porém de forma inadequada. Exemplos:

a. Quebra de tijolos, devido à falta dos mesmo com tamanho adequado;

b. Recortes de pisos;

c. Espessura excessiva de revestimento;

d. Posicionamento de material em locais inadequados.

\section{Legislações}

Neste tópico será descrito: leis, normas, decretos e portarias relacionados diretamente ou indiretamente

Tabela 2. Legislações Federais Sobre Resíduos Sólidos.

\begin{tabular}{|c|c|}
\hline $\mathrm{N}^{\circ}$ & Assunto \\
\hline Lei $n^{\circ} 11.445$, de 05 de janeiro de 2017 & $\begin{array}{l}\text { Estabelece diretrizes para o saneamento básico; alterando as Leis } \\
\mathrm{n}^{\circ} 6.766 \text {, de } 19 \text { de dezembro de } 1979,8.036 \text {, de } 11 \text { de maio de } \\
199,8666 \text {, de } 21 \text { de junho de } 1993,8987 \text {, de } 13 \text { de fevereiro de } \\
\text { 1995; revoga a Lei } n^{\circ} 6.528 \text {, de } 11 \text { de maio de } 1978 \text {; }\end{array}$ \\
\hline Lei $n^{\circ} 12.305$, de 02 de agosto de 2010 & $\begin{array}{l}\text { Institui a Política Nacional de Resíduos Sólidos; altera a Lei }{ }^{\circ} \\
\text { 9.605, de } 12 \text { de fevereiro de } 1998 \text {; }\end{array}$ \\
\hline Decreto $n^{\circ} 7.404$, de 23 de dezembro de 2010 & $\begin{array}{l}\text { Regulamenta a Lei } n^{\circ} 12.305 \text {, de } 02 \text { de agosto de } 2010 \text {, que } \\
\text { institui a Política Nacional de Resíduos Sólidos, cria o Comitê } \\
\text { Interministerial da Política Nacional de Resíduos Sólidos e o } \\
\text { Comitê Orientador para Implantação do Sistema de Logística } \\
\text { Reversa. }\end{array}$ \\
\hline
\end{tabular}

Fonte:(Prefeitura Municipal de Fortaleza, 2003). 
com a administração dos resíduos sólidos gerados na construção civil. Podendo-se compreender algumas definições e as classes desses resíduos, gerados dentro da construção.

\section{Legislação Federal}

\section{Lei $\mathbf{n}^{0}$ 11.445 - Diretrizes nacionais para saneamento básico}

Segundo a Lei Nacional n ${ }^{\circ}$ 11.445/07:

\begin{abstract}
"Saneamento básico um conjunto de serviços, infraestruturas ou equipamentos. c) limpeza urbana e manejo de resíduos sólidos: conjunto de atividades, infraestruturas e instalações operacionais de coleta, transporte, transbordo, tratamento e destino final do lixo doméstico e do lixo originário da varrição e limpeza de logradouros e vias públicas."
\end{abstract}

Esta lei elabora políticas para eficiência do saneamento básico, tais como:

a. Projetos de saneamento básico, segundo a Lei;

b. Consolida direitos e deveres dos utilizadores;

c. Interferir serviços que não estejam a seguir os parâmetros;

d. Permissão de retomada de serviço;

Fiscalização.

\section{Lei $\mathbf{n}^{0} \mathbf{1 2 . 3 0 5 / 1 0}$}

\section{A Lei ${ }^{\circ} 12.305$, define-se como:}

“Art. $1^{\circ}$. Esta Lei institui a Política Nacional de Resíduos Sólidos, dispondo sobre seus princípios, objetivos e instrumentos, bem como sobre as diretrizes relativas à gestão integrada e ao gerenciamento de resíduos sólidos, incluídos os perigosos, às responsabilidades dos geradores e do poder público e aos instrumentos econômicos aplicáveis. $\S 1^{\circ}$. Estão sujeitas à observância desta Lei as pessoas físicas ou jurídicas, de direito público ou privado, responsáveis, direta ou indiretamente, pela produção de destroços sólidos e as que desenvolvam ações relacionadas à gestão integrada ou ao gerenciamento de resíduos sólidos".

Entre os seus princípios, inclui-se:

a. Prevenções e cuidados;

b. Desenvolvimento sustentável;

c. Gestão dos resíduos visando os parâmetros: sócias, econômicos, tecnológicos, culturais e da saúde;

d. Visar o poluidor como um devedor e quem preserva, um beneficiário;

e. Dispor da assistência de todos os órgãos, tanto público e privado, e quaisquer segmento relacionado a sociedade;

f. A constatação que a reutilização dos resquícios sólidos não só é um bem econômico, como se gera ganhos financeiros e na cidadania;

g. Valorização da diversidade local e da região.

Os seus objetivos são:

a. Possuir uma saúde pública e ambiental de qualidade;

b. Geração de resíduo nula, ou redução/reciclagem dos resíduos gerados;

c. Estar em constante busca de novas técnicas, para ser implantadas na minimização de impactos desses resíduos;

d. Estímulo a padrões e serviços sustentáveis, obtendo melhoria da eficiência energética e da proteção ao meio ambiente;

e. Incentivo a indústria de aproveitamento do material, fazendo 'marketing' do consumo de reciclável;

f. Esta Lei decreta que os estados e municípios necessitam das suas normas, decretos e diretrizes de redução de resíduos, manuseio, transporte e destinação adequada.

\section{Decreto $n^{0} 7.404$}

\section{Conforme com este Decreto:}

\begin{abstract}
"Art. $1^{\circ}$ Este Decreto estabelece normas para execução da Política Nacional de Resíduos Sólidos, de que trata a Lei no 12.305, de 2 de agosto de 2010 Art. $2^{\circ}$ A Política Nacional de Resíduos Sólidos integra a Política Nacional do Meio Ambiente e articula-se com as diretrizes nacionais para o saneamento básico e com a Política Federal de Saneamento Básico, nos termos da Lei no 11.445, de 5 de janeiro de 2007, com a Lei no 11.107, de 6 de abril de 2005, e com a Política Nacional de Educação Ambiental, regulada pela Lei no 9.795, de 27 de abril de 1999".
\end{abstract}

As disposições gerais referentes a essa lei tratase de estabelecer a responsabilidade das pessoas físicas e jurídicas com os resíduos sólidos, tendo consciência que o ciclo de vida dos produtos que geram resíduos é dos mesmos consumidores/empresas. Quem compra os produtos seja ele pessoa física ou jurídica tem como responsabilidade o fracionamento, afastamento e destinação desses resquícios de formas corretas, estabelecidas nas diretrizes municipais/estaduais. Estabelecendoopoderpúblicocomo unidaderesponsável observar e controlar a coleta adequada desses resíduos.

Em conformidade com o Art. 9, a Coleta Seletiva é a segregação dos resíduos sólidos conforme de acordo com as suas características. Para melhoria dessa coleta, a uma política de implantação de logística reversa, que seria estabelecer essas diretrizes e criar acordos com as empresas que produzem esses resíduos.

\section{CONAMA}

O Conselho Nacional do Meio 
Ambiente(CONAMA) estabelece a Política Nacional do Meio Ambiente, este órgão existe para o estudo, auxílio e apresentação, ao Governo, orientações de sistemas governamentais para os recursos naturais e o meio ambiente, visando tanto a preservação quanto a utilização dos mesmos.

Tabela 3. Resoluções do CONAMA.

\begin{tabular}{ll}
\hline & \\
\hline Resolução $n^{\circ} 237$, de 19 de dezembro de 1997. & Licenciamento Ambiental \\
Resolução ${ }^{\circ} 307$, de 5 de julho de 2002. & Estabelece Diretrizes, critérios e procedimentos \\
& para a gestão de resíduos da construção civil; com \\
& alterações feitas no decorrer do tempo até hoje.
\end{tabular}

Fonte: (Prefeitura Municipal de Fortaleza, 2003).

\section{Resolução n 237}

Esta Resolução vem com o objetivo estabelecer a necessidade do Licenciamento Ambiental para atuação do serviço (autorização da obra), visando a qualidade ambiental e desenvolvimento sustentável, tendo sempre o dever de se buscar melhoria contínua do processo deste descarte. Sendo assim cabe ao responsável pela obra, antes de começar a efetivação dos serviços procurar a Câmara municipal da cidade, onde se encontra o Manual de Obra, se adequar as regras, diretrizes e solicitações para assim pedir junto a prefeitura o seu Licenciamento, podendo assim iniciar a sua construção.

\section{Resolução no 307}

Segundo com o CONAMA 307/02 é:

“Art. $1^{\circ}$ Estabelecer diretrizes, critérios e procedimentos para a gestão dos resíduos da construção civil, disciplinando as ações necessárias de forma a minimizar os impactos ambientais". E classifica gerenciamento de resíduos sólidos como: "XI - Gerenciamento de resíduos sólidos: conjunto de ações exercidas, direta ou indiretamente, nas etapas de coleta, transporte, transbordo, tratamento e desfecho ambientalmente adequada dos resíduos sólidos e disposição final ambientalmente adequada dos rejeitos, de acordo com plano municipal de gestão integrada de resíduos sólidos ou com plano de gerenciamento de resíduos sólidos, exigidos na forma da Lei $\mathrm{n}^{\circ} 12.305$, de 2 de agosto de 2010;(nova redação dada pela Resolução 448/12)".

Segundo CONAMA 307, os resíduos podem ser subdivididos em 4 classes, A, B, C e D) com as alterações realizadas, mostradas na tabela 3 . Que são definidas como:

Classe A: São componentes dos quais podem ser reutilizados como agregados, sendo retirados da construção. Podendo ser: Tijolos, telhas, tijolos, concreto etc.

Classe B: São resquícios que também podem ser reciclados, porém com outras finalidades. Exemplos: materiais plásticos, madeira, vibro, gesso etc.

Classe C: Para materiais dessa classe, não foram construídos meios que possam fazer a reciclagem dos mesmos.

Classe D: São resíduos perigosos provenientes da construção civil, que podem causar riscos. Como: tintas, solventes, produtos com amianto, ou qualquer rejeito que cause danos à saúde.

Para se destinar esses resíduos adequadamente são necessários passarem pelas seguintes etapas:

Caraterização: Identificação e cálculo da quantificação dos resíduos;

Triagem: Definir a que classe o material se encaixa. Esta etapa deve ser feita na fonte de concepção do resíduo. Na norma da ABNT 15112, também é citada a necessidade deste passo.

Acondicionamento: É de responsabilidade de quem gera o resíduo armazená-lo de forma adequada até o momento do reuso/reciclagem ou destinação (transporte) para local adequado;

Transporte: Necessita ser realizado depois das etapas 


\section{Fluxograma 2. Estrutura de Resíduos da Construção Civil.}

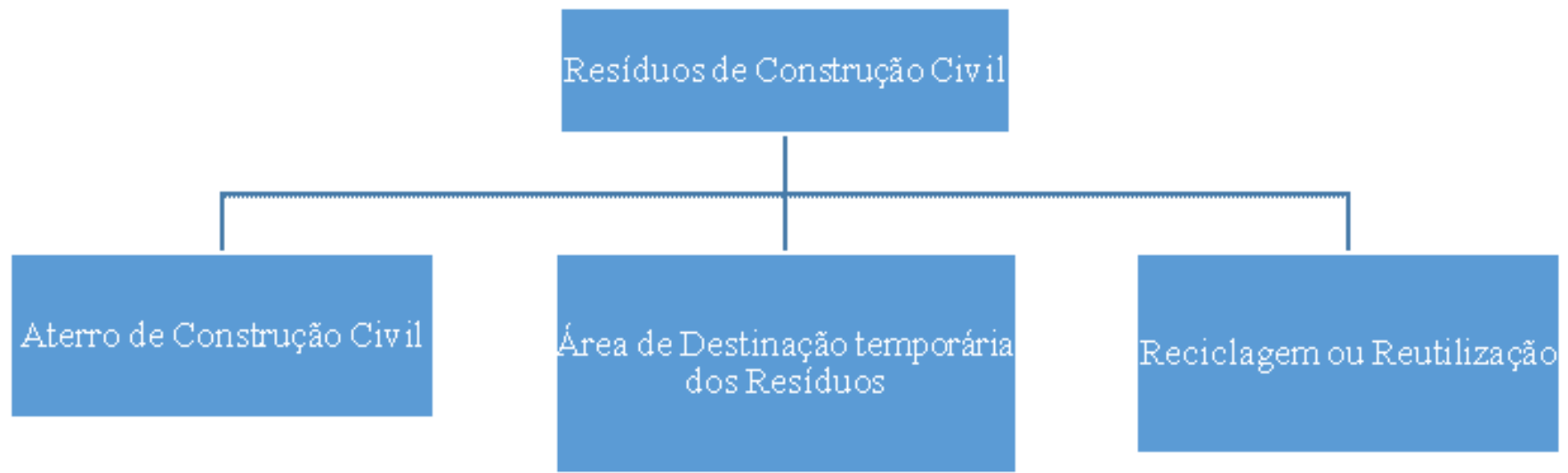

Fonte: Silva e Silva (2016).

Fluxograma 3. Fluxograma de processo de destinação dos resíduos da construção civil.

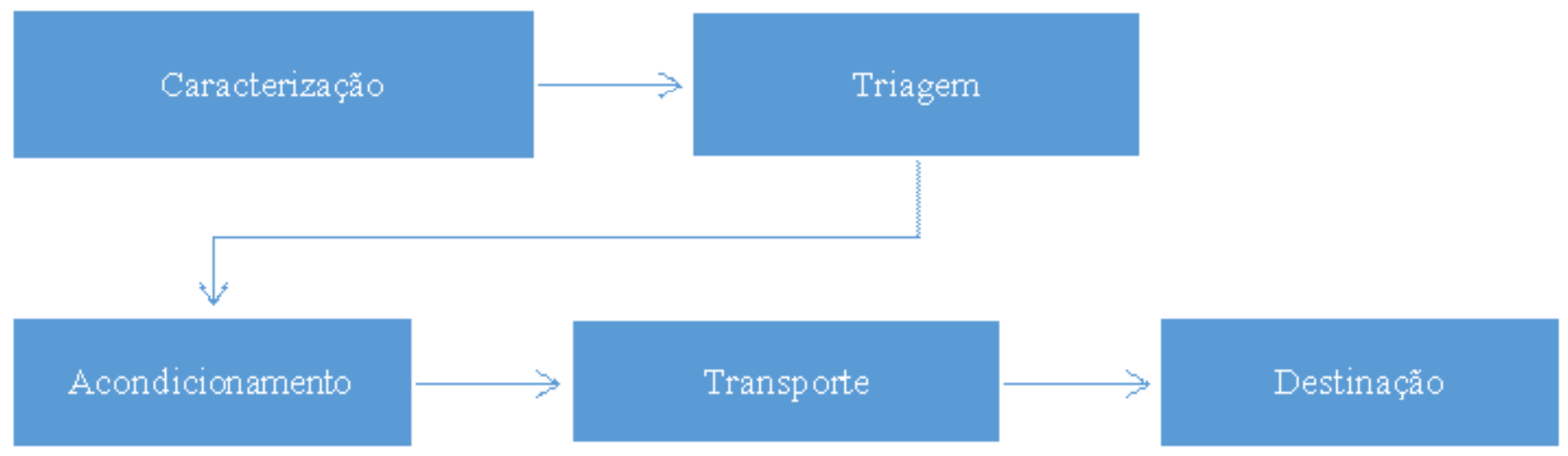

Fonte: Próprio autor.

acima, seguindo as normas vigentes de transportes de resíduos;

Destinação: Locais adequados, sendo descrito abaixo, de acordo também com a ABNT 15114.

No Art. ${ }^{\circ} 10$. Relata que esses resíduos, deveram ser designados para:

"I - Classe A: deverão ser reutilizados ou reciclados na forma de agregados ou encaminhados a aterro de resíduos classe A de preservação de material para usos futuros; (nova redação dada pela Resolução 448/12);

II - Classe B: deverão ser reutilizados, reciclados ou encaminhados a áreas de armazenamento temporário, sendo dispostos de forma a permitir a sua utilização ou reciclagem futura;

III - Classe C: deverão ser armazenados, transportados e destinados em conformidade com as normas técnicas específicas;

IV - Classe D: deverão ser armazenados, transportados e destinados em conformidade com as normas técnicas específicas (nova redação dada pela Resolução 448/12)".

\section{Normas da ABNT \\ 10004/04 - Classificação de Resíduos Sólidos}

São classificados de acordo com os riscos que traz para saúde e para o meio ambiente, podendo ser caracterizado como perigosos ou não:

Perigosos: Que trazem riscos à saúde pública e ambiental. Sendo materiais: inflamáveis, corrosivos, reativos, tóxicos, com agentes patogênicos.

Não Perigosos: Que não causam riscos, podendo ser inertes e não inertes.

a. Não inertes: Biodegradáveis, combustíveis e solúveis a água;

b. Inertes: Segundo a ABNT 10007;

"Quaisquer resíduos que, quando amostradas de uma forma 
representativa, segundo a ABNT 10007, e submetidos a um contatodinâmicoeestáticocomáguadestilada ou deionizada,a temperatura ambiente, conforme ABNT 10006, não tiver em nenhum de seus constituintes solubilizados as concentrações superiores aos padrões de potabilidade de água, efetuando-se aspecto, cor, turbidez, dureza e Sabor, conforme anexo G”.

Para se classificar a espécie de resíduo de acordo com a sua periculosidade, pode-se utilizar o fluxograma abaixo.
$15113 / 2004$

Conforme com a Norma da ABNT 15113/04:

"1.1 Esta Norma fixa os requisitos mínimos exigíveis para projeto, implantação e operação de aterros de resíduos sólidos da construção civil classe A e de resíduos inertes; 1.2 Esta Norma visa a preservação de materiais de forma segregada, possibilitando o uso futuro ou, ainda, a disposição destes materiais, com vistas à futura utilização da área".

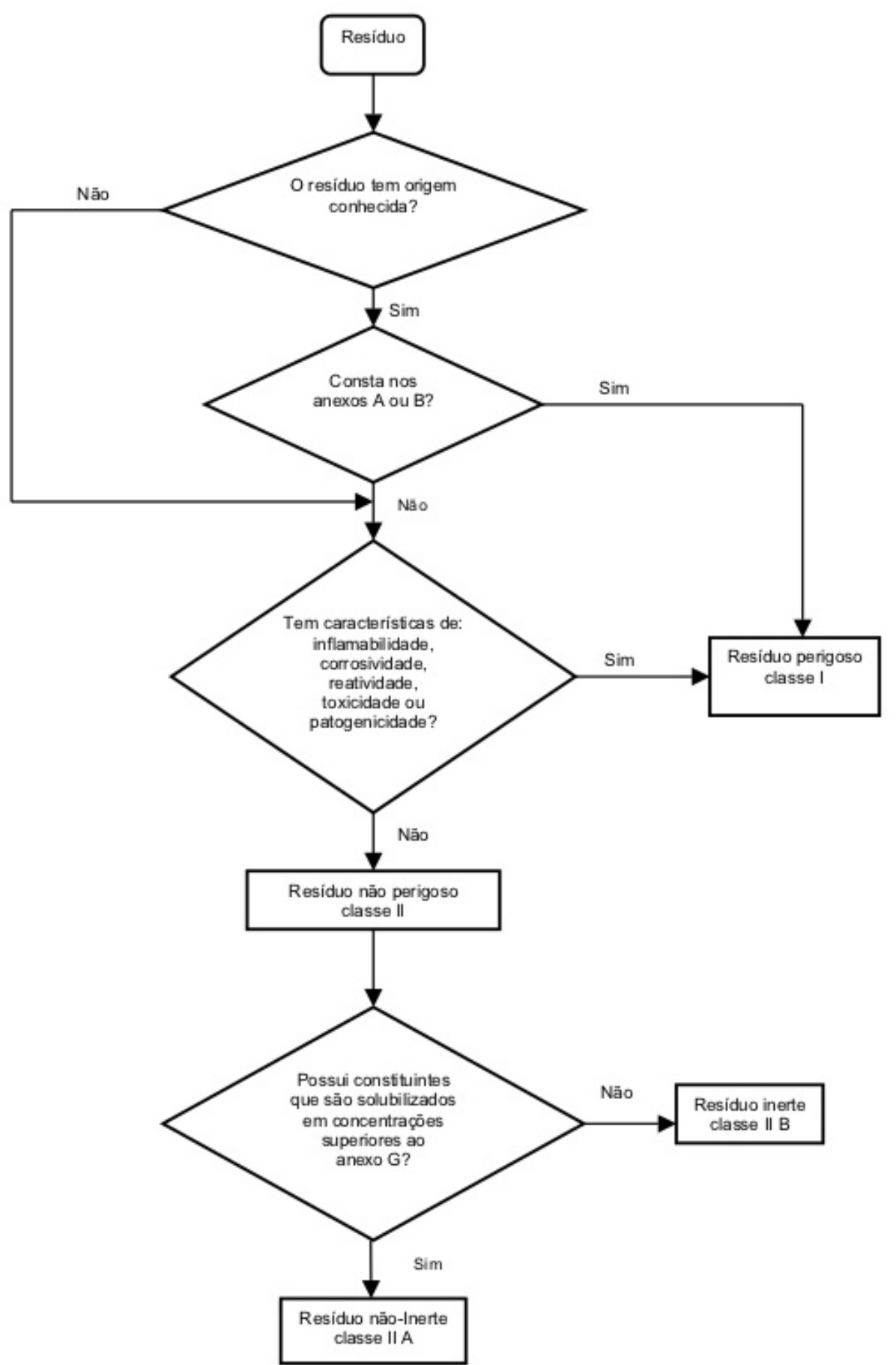

Figura 3. Caracterização e Classificação de Resíduos.

Fonte: ABNT 10004/04. 
O local escolhido, deve ter alguns parâmetros de localidade e acesso. Tais que, o local escolhido deve ter: baixa população ao redor, os impactos ambientas devem ser mínimos e esteja de acordo com a legislação de uso de solo e ambiental. Sendo observado: as vias de acesso, vegetação, geologia adequada, volume ocupacional etc. Já relacionado ao acesso, o ambiente deve ser sinalizado, sem entrada de pessoas comuns e animais, ter proteção as mudanças climáticas.

\section{Gestão de Resíduos}

\section{Fluxo de geração de insumos a destinação final}

\section{Segregação}

Nesta etapa é importante ressaltar a importância da limpeza, organização e da separação dos resíduos dentro do canteiro de obra, uma vez que ambos estão diretamente relacionados a perdas no dia a dia do serviço, pois a sua boa otimização gera redução desses resíduos.

Entre diversos benéficos de ter o serviço limpo e arrumado, os que estão diretamente relacionados a perda são:

a. Com uma boa organização é possível se identificar o resíduo na sua geração, fazendo com que além de identificar os principais geradores, possa se reaproveitá-lo antes de destiná-lo ao descarte;

b. Evite a junção de resíduos recicláveis com não recicláveis, evitando refazer o trabalho ou até a destinação de materiais não apropriados para reciclagem;

c. Impossibilita a probabilidade de mandar matériasprimas para reciclagem;

d. Baixa perda de materiais prontos sendo descartados por falta de uso;

e. Além desses ganhos relacionados a minimização de perdas, a ganhos relacionados a otimização ambiente de trabalho, como:

f. Reduzir os incidentes de trabalho, relacionado a desorganização na construção;

g. Satisfação do funcionário, que está diretamente ligado a aumento da produtividade e baixa rotatividade deles;

h. Estoque sobre controle e melhoria no uso.

\section{Acondicionamento}

Após a segregação desses materiais, deveram ser acondicionados no local de geração, em ambientes adequados para cada espécie de resíduo específico, até seu transporte para destinação adequada.

Materiais como vidro, madeira, plásticos devem ser armazenados e bombonas ou algum recipiente aberto, podendo-se colocar sacolas de ráfia com um pedaço para fora com a intenção de facilitar o recolhimento para sua destinação adequada. Já os entulhos mais pesados e/ou com grandes volumes, devem ser armazenados em caçambas estacionarias que são contratadas por empresas privadas ou baias fixas.

Os materiais orgânicos devem ser guardados em locais fechados em sacolas normais.

Sendo que é necessário o emprego de etiquetas com especificação e cor adequado para cada espécie de resíduos conforme o CONAMA 275, sendo elas:

Marrom - Resíduos orgânicos;

Laranja - Resíduos Perigosos;

Cinza - Resíduos não recicláveis, ou misturados, ou que teve algum tipo de contaminação;

Amarelo - Metal;

Azul - Papel;

Preto Madeira;

Branco - Resíduos de ambulatório e serviços da saúde;

Roxo - Resíduos Radioativos;

Verde - Vidro;

Vermelho - Plástico.

Abaixo podemos ver, as relações dos materiais e seus locais de acondicionamento adequado até destinação final.

A acondicionação final necessita ser feito de maneira que facilite na hora da coleta do transporte, porem sempre respeitando as classes destes materiais e suas segregações. Exemplos de possíveis recipientes:

\section{- Big bags}

Segundo Livro de Gestão de Resíduos - SENAI:

\begin{abstract}
"Os big bags podem ser utilizados no acondicionamento de papeis, plásticos e outros materiais leves como fardamentos, luvas, botas etc. O tamanho recomendado para os bags é de $90 \mathrm{~cm}$ x $90 \mathrm{~cm}$ x $120 \mathrm{~cm}$. O local dos bags deve ser coberto e protegido de chuva, pois resíduos de papel e papelão perdem a possibilidade de reciclagem se molhados. Devem ser construídos suportes para o posicionamento dos bags, que podem ser metálicos ou em madeira e podem ser construídos no próprio canteiro. A finalidade do suporte é manter o bag aberto, portanto o bag deve estar apoiado no chão, e não suspenso. É recomendado o uso de dobradiças ou dispositivos de encaixe na parte frontal do suporte para facilitar a retirada do bag. A sinalização do material a ser acondicionado no bag deve estar presa ao suporte.O suporte deve ter altura aproximada de 1,60 m e largura de 1,20 m. É importante sempre confirmar as dimensões após a aquisição dos bags".
\end{abstract}

\section{- Baias}

São recipientes para o armazenamento de resíduos pesados, de Classe A, madeira ou metais, suas dimensões são determinadas conforme com a necessidade da 
Tabela 4. Acondicionamento Adequado dos Materiais.

\begin{tabular}{|c|c|}
\hline Tipo de Resíduo & Acondicionamento Inicial \\
\hline $\begin{array}{l}\text { Blocos de concreto, blocos cerâmicos, argamassas, } \\
\text { componentes cerâmicos, concreto, tijolos e similares. }\end{array}$ & $\begin{array}{l}\text { Pilhas formatadas próximas aos locais de transporte } \\
\text { interno, nos respectivos pavimentos. }\end{array}$ \\
\hline Madeira & $\begin{array}{l}\text { Bombonas ou pilhas formatadas nas proximidades da } \\
\text { própria bombona ou dos dispositivos de transporte } \\
\text { vertical. }\end{array}$ \\
\hline Plásticos (embalagens, aparas de tubulações etc.) & Bombonas ou fardos \\
\hline $\begin{array}{l}\text { Papelão (sacos e caixas de embalagens utilizados) e } \\
\text { papéis (escritório) }\end{array}$ & Bombonas ou fardos \\
\hline Metal (ferro, aço, fiação, arame etc.) & Bombonas \\
\hline Serragem & Sacos de ráfia próximas aos locais de geração \\
\hline Gesso de revestimento, placas e artefatos & $\begin{array}{l}\text { Sacos de embalagem de gesso ou sacos de ráfia } \\
\text { próximos aos locais de geração. }\end{array}$ \\
\hline Solos & Eventualmente em pilhas para imediata remoção. \\
\hline Telas de fachada e de proteção & $\begin{array}{l}\text { Recolher após o uso e dispor em local adequado, sendo } \\
\text { este já para acondicionamento final. }\end{array}$ \\
\hline EPS (poliestireno expandido) - ex.: isopor & $\begin{array}{l}\text { Quando em pequenos pedaços, colocar em sacos de } \\
\text { ráfia. Em placas, formar fardos. }\end{array}$ \\
\hline $\begin{array}{l}\text { Residuos perigosos presentes em embalagens plásticas, } \\
\text { instrumentos de aplicação (pincéis, broxas e trinchas) e } \\
\text { outros materiais auxiliares (panos, trapos, estopas etc.) }\end{array}$ & $\begin{array}{l}\text { Manuseio com os cuidados observados pelo fabricante } \\
\text { do insumo na ficha de segurança da embalagem ou do } \\
\text { elemento contaminado do instrumento de trabalho, } \\
\text { imediato transporte pelo usuário para o local de } \\
\text { acondicionamento final. }\end{array}$ \\
\hline $\begin{array}{l}\text { Restos de uniformes, botas, panos e trapos sem } \\
\text { contaminação por produtos químicos. }\end{array}$ & $\begin{array}{l}\text { Disposição nas bags para resíduos diversos sendo este o } \\
\text { acondicionamento final. }\end{array}$ \\
\hline
\end{tabular}

Fonte: (Livro de Gestão de Resíduos, SENAI).

obra. Podendo ser baias móveis (caixas, normalmente de madeira, com a parte superior aberta para recolher os materiais facilmente) ou baias fixas (fixada no cão, frequentemente construídas de madeiras).

\section{- Caçambas estacionarias}

Essas caçambas auxiliam o recolhimento dos resíduos, segundo a ABNT NBR 14728:2005 essa caçamba pode ser ou não aberta, sua eficiência normalmente suporta $3 \mathrm{~m}^{3}, 4 \mathrm{~m}^{3}, 5 \mathrm{~m}^{3}$ e $7 \mathrm{~m}^{3}$, podendo variar $\pm 10 \%$ para com tampa. Sendo postas em locais de fácil retirada, para os caminhões de transporte. Alguns planos de gerenciamentos de resquícios de alguns municípios não permitem que as posicionem nas calçadas. 


\section{Transporte}

Para Cabral (2001), como relatado no Manual sobre os Resíduos Sólidos da Construção Civil, é de estrema importância o manuseio adequado no transporte interno, para que não haja perdas desnecessárias ou desorganização dos resíduos, podendo ter contaminação cruzada.

Em geral, o deslocamento horizontal dos resíduos é realizado em carrinhos-de-mão e giricas; e o deslocamento vertical é realizado em tubos condutores de entulho ou elevadores de carga. Caso o volume de resíduos seja muito grande, usa-se a grua para o transporte vertical.

Já o transporte externo é realizado por transportadores terceirizadas, licenciadas e credenciada na prefeitura do município, para esse determinado serviço, que é direcionar os resíduos para seu destino adequado.

\section{Destinação Final}

Conforme o CONAMA 307, os resíduos classificados como Classe A devem ser reutilizados como agregados dentro da própria obra ou direcionados

Tabela 5. Tipos de Resíduo x Transporte Interno.

\begin{tabular}{|c|c|}
\hline Tipos de residuos & Transporte \\
\hline $\begin{array}{l}\text { Blocos de concreto, blocos cerâmicos, argamassas, } \\
\text { outros componentes cerâmicos, concreto e } \\
\text { assemelhados. }\end{array}$ & $\begin{array}{l}\text { Carrinhos ou gericas para deslocamento horizontal e } \\
\text { condutor de entulho, elevador de carga ou grua para } \\
\text { transporte vertical. }\end{array}$ \\
\hline Madeira & $\begin{array}{l}\text { Grandes volumes: transporte manual (em fardos) com } \\
\text { auxilio de gericas ou carrinhos associados a elevador de } \\
\text { carga ou grua. }\end{array}$ \\
\hline Plástico, papelão, papéis, metal, serragem e EPS. & $\begin{array}{l}\text { Transporte dos residuos contidos em sacos, bags ou em } \\
\text { fardas com o auxilio de elevador de carga ou grua, } \\
\text { quando necessário. }\end{array}$ \\
\hline Gesso de revestimento, placas, acartuchadas e artefatos & $\begin{array}{l}\text { Carrinhos ou gericas para deslocamento horizontal e } \\
\text { elevador de carga ou grua para transporte vertical. }\end{array}$ \\
\hline Solos & $\begin{array}{l}\text { Equipamentos disponiveis para escavação e transporte } \\
\text { (pá-carregadeira etc.). Para pequenos volumes, carrimhos } \\
\text { egericas. }\end{array}$ \\
\hline
\end{tabular}

Fonte: Pinto et al., 2005.

para aterros específicos para materiais de construção civil.

Já os resíduos de Classe B, C, D tem destinos distintos, não especificado na resolução, porem especifica que assim como a segregação e acondicionamento a destinação deve ser feita separada e para locais que tenha cuidado específico. 


\section{Infrações à legislação de Resíduos da Construção Civil} 1998:

Segundo a Lei $\mathrm{N}^{\circ}$ 9.605, de 12 de fevereiro de

“Art. $2^{\circ}$ Quem, de qualquer forma, concorre para a prática dos crimes previstos nesta Lei, incide nas penas a estes cominadas, na medida da sua culpabilidade, bem como o diretor, o administrador, o membro de conselho e de órgão técnico, o auditor, o gerente, o preposto ou mandatário de pessoa jurídica, que, sabendo da conduta criminosa de outrem, deixar de impedir a sua prática, quando podia agir para evitá-la". Art. $3^{\circ}$ As pessoas jurídicas serão responsabilizadas administrativa, civil e penalmente conforme o disposto nesta Lei, nos casos em que a infração seja cometida por decisão de seu representante legal ou contratual, ou de seu órgão colegiado, no interesse ou benefício da sua entidade".
Sendo assim, para análise da gravidade de penalidade e sua imposição, são necessárias análises dos danos à saúde pública e ao meio ambiente, os crimes ambientais relacionados e o cenário financeiro do responsável, caso haja necessidade de multa.

\section{As penas podem ser:}

Multas: Podem variar de $\mathrm{R} \$ 50,00$ a $\mathrm{R} \$ 500,00$ para pessoas físicas e de $\mathrm{R} \$ 500,00$ a 2 milhões por pessoas jurídicas;

Restritivas de direitos: Recolhimento domiciliar; interdição temporária dos direitos; intervenção por partes ou total das atividades;

Prestação de serviços à comunidade.

Tabela 6. Destinação ou Utilização dos Resíduos da Construção Civil.

\begin{tabular}{|c|c|}
\hline Materiais & Destinação/utilização \\
\hline Entulho de concreto & $\begin{array}{l}\text { Construção de estradas; solos de aterros; Meio fio; } \\
\text { Concreto asfáltico; Blocos de vedações; Concretos etc. }\end{array}$ \\
\hline Madeira & $\begin{array}{l}\text { Pode ser reutilizada caso não esteja suja ou quebrada; } \\
\text { Combustivel; Triturada para criação de papeis e } \\
\text { papelões etc. }\end{array}$ \\
\hline Papel, plástico e papelão & Podem ser doados para catadores locais; \\
\hline Vidro & $\begin{array}{l}\text { Pode ser utilizado como novo vidro na fabricação de } \\
\text { novos materiais como: telhas, fibra de vidro, aditivos } \\
\text { para asfalto etc. }\end{array}$ \\
\hline Resíduos de alvenaria & $\begin{array}{l}\text { Criação de concreto; Fabricação de novos tijolos; Cinzas } \\
\text { para uso na área; }\end{array}$ \\
\hline Sacos de cimento & Combustivel; \\
\hline Gesso & Pó de gesso para reuso; Corretivo de solo; \\
\hline
\end{tabular}

Fonte: (Livro de Gestão de Resíduos, SENAI). 


\section{Infrações de Penalidade Civil}

Em conformidade com Art. 225 da constituição federal de 1988, o que representa responsabilidade civil são:

- Conduta. Podendo ser comissiva, quando se faz algo que é proibido conforme a lei, ou, omissiva, quando não se cumpre algo que é estipulado como obrigatório;

“a) prejudiquem a saúde, a segurança e o bem-estar da população;

b) criem condições adversas às atividades sociais $e$ econômicas;

c) afetem desfavoravelmente a biota;

d) afetem as condições estéticas ou sanitárias do meio ambiente;

e) lancem matérias ou energia em desacordo com os padrões ambientais estabelecidos".

- Ligação entre o dano e causa: É necessário ter algum dano para se esta caracterizar responsabilidade. Pois, quando a essa responsabilidade, é de obrigação dos responsáveis ressarci-los.

\section{Crimes ambientais}

Os crimes ambientais podem ser classificados de 5 formas, segundo a Lei 9.605/98:

Contra Fauna: são crimes que agridem a vida dos animais ou do seu 'habitat', podendo assim causar morte por poluição;

Contra Flora: destruir ou causar algum tipo dano a vegetação, ou sua regeneração. Destruir qualquer ambiente público que possua vegetação;

Poluição ou outros crimes ambientais: a VGresíduos, 2017, define este tópico como:

\begin{abstract}
"todas as atividades humanas que produzem poluentes (lixo, resíduos e outros), serão considerados crime ambiental de passível de penalização com poluição acima dos limites estabelecidos na legislação. Também é atividade criminosa a poluição que provoque danos à saúde humana, mortandade de animais e destruição à flora. Também aquela atividade que torne impróprio para o uso ou ocupação humana, a poluição hídrica que torne necessária a interrupção do abastecimento público e não adoção de medidas preventivas em caso de dano ambiental grave ou irreversível."
\end{abstract}

Também são denominados crimes ambientais qualquer despejo, e/ou armazenagem de resíduos, tóxicos ou nocivos à saúde.

Contra a administração ambiental: todo aquele que não realiza alguma obrigação referente ao meio ambiente seja por lei ou contrato, ou que complica a fiscalização do meio ambiente.

Infração administrativa: São qualquer violação a regras ou leis jurídicas, que impede de usufruírem, proteger ou recuperar o meio ambiente.

\section{Conclusão}

Em relação ao descarte adequado dos Resíduos da Construção Civil, as legislações vigentes e os CONAMAS são bem específicos em relação aos parâmetros e regras a serem seguidos, direcionando suas diretrizes, métodos e penalidades vigentes. Porém, os grandes problemas relacionados ao cumprimento destas leis e normas, são relacionados a falta de fiscalização contínua e eficaz, e o processo de aculturamento tanto de pessoas físicas e jurídicas em relação ao descarte e manuseio adequado desses resíduos.

Sendo assim, é de estrema importância que o responsável pela atividade da obra (o engenheiro) gerencie esses resquícios de forma adequada e habilite esta cultura dentro da construção civil, não só por conta da produtividade do serviço, e sim, de acordo com a legislação, que é bem consistente em relação às penalidades. Podendo os responsáveis pagarem multas e/ou ficarem suspensos de suas atividades, podendo até ocorrer embargo da obra ou demolição.

\section{Referências Bibliográficas}

Abrelpe (2017). PANORAMA DOS RESÍDUOS SOLIDOS NO BRASIL, v (4), 1-74. Acessado em 22 de março, 2019.https://belasites.com.br/clientes/ abrelpe/site/wp-content/uploads/2018/09/SITE_grappa_panoramaAbrelpe ago_v4.pdf

Costa, A. L., \& Formoso, C. T. (1999). Perdas na construção civil: uma proposta conceitual e ferramentas para prevenção. Anais do VII Encontro Nacional de Tecnologia do Ambiente Construído-Qualidade no processo construtivo UFSC/ANTAC. Florianópolis-SC, 27, 1-7.

Decreto Federal $n^{0}$ 7.404/10 (2010). Normas para execução da Política Nacional de Resíduos Sólidos, de que trata a Lei no 12.305, de 2 de agosto de 2010.

Karpinsk, L. A. (2009). Gestão diferenciada de resíduos da construção civil: uma abordagem ambiental. Edipucrs.

Lei Federal $n^{\circ} 9605$ (1998). Dispõe sobre as sanções penais e administrativas derivadas de condutas e atividades lesivas ao meio ambiente, e dá outras providências.

Lei Federal $n^{\circ} 6514$ (2008). Dispõe sobre as infrações e sanções administrativas ao meio ambiente, estabelece o processo administrativo federal para apuração destas infrações, e dá outras providências.

Lei Federal n¹2.305/10 (2010). Política Nacional dos Resíduos Sólidos.

Lei Federal $n^{\circ} 11.445 / 07$ (2007). Diretrizes nacionais para o saneamento básico e para a política federal de saneamento básico.

Meira, A. R., Librelotto, L. I., Santos, P. L., \& Heineck, L. F. M. (1998) Metodologia para redução das perdas na Construção Civil.

Norma da ABNT 10004/04 (2004). Resíduos sólidos - Classificação.

Norma da ABNT 15112/04 (2004). Resíduos da construção civil e resíduos volumosos - área de transbordo e triagem - diretrizes para projetos, implantação e operação.

Norma da ABNT 15113/04 (2004). Resíduos da construcão civil e resíduos inertes - aterros - diretrizes para projetos, implantação e operação. 2004.

Norma da ABNT 15114/04 (2004). Resíduos sólidos da construção civil Áreas de reciclagem - Diretrizes para projeto, implantação e operação. 
Pinto, T. D. P., \& Gonzáles, J. L. R. (2005). Manejo e gestão de resíduos da construção civil. Manual de orientação, 1 .

Resolução n 237/97 (1997). O CONSELHO NACIONAL DO MEIO

AMBIENTE - CONAMA, no uso das atribuições e competências que lhe são conferidas pela Lei $\mathrm{n}^{\circ} 6.938$, de 31 de agosto de 1981, regulamentadaspelo Decreto $\mathrm{n}^{\circ}$ 99.274, de 06 de junho de 1990, e tendo em vista o disposto em seu Regimento Interno.

Resolução CONAMA 307/02 (2002). Estabelece diretrizes, critérios e procedimentos para a gestão dos resíduos da construção civil.

Resolução no 431/11 (2011). Altera o Artg. $3^{\text {a }}$ da Resolução no ${ }^{\mathbf{3} 07}$, de 05 de julho de 2002, do Conselho Estadual do Meio Ambiente - CONAMA, estabelecendo nova classificação para o gesso.

Resolução $n^{\circ}$ 348/04 (2004). Altera a resolução CONAMA 307, de 05 de julho de 2002, do Conselho Estadual do Meio Ambiente - CONAMA, incluindo o amianto na classe de resíduos perigosos.

Resolução n ${ }^{\circ} 448 / 12$ (2012). Altera o Artg. $\mathbf{2}^{\mathbf{a}}, \mathbf{4}^{\mathbf{a}}, \mathbf{5}^{\mathbf{a}}, \mathbf{6}^{\mathbf{a}}, \mathbf{8}^{\mathbf{a}}, \mathbf{9}^{\mathbf{a}}, \mathbf{1 0 ^ { \mathbf { a } }}$ e 11 da Resolução n ${ }^{0}$ 307, de 05 de julho de 2002, do Conselho Nacional do Meio Ambiente-CONAMA.

VGresíduos (2017). Práticas que geram multas no gerenciamento dos resíduos - V (1), 1. Recuperado em 5 de maio, 2019. https://www.vgresiduos. com.br/blog/praticas-que-geram-multas-no-gerenciamento-dos-residuos/

Zordan, S. E. (1997). A utilização do entulho como agregado, na confecção do concreto. $T$ 